\title{
Teores de flúor em mananciais e na rede de abastecimento público de municípios de Pernambuco, Brasil
}

\author{
Fluoride levels in springs and water sources and in the public supply \\ networks of municipalities in the State of Pernambuco, Brazil
}

Chrisley Mariany Onduras de Freitas (https://orcid.org/0000-0002-9142-6730) ${ }^{1}$ Petrônio José de Lima Martelli (https://orcid.org/0000-0001-6920-6435) ${ }^{2}$

Nilcema Figueiredo (https://orcid.org/0000-0001-6181-8728) ${ }^{2}$

Grasiele Fretta Fernandes (https://orcid.org/0000-0001-6182-1126) ${ }^{3}$

Mikael Lima Brasil (https://orcid.org/0000-0002-2006-6934) ${ }^{4}$

${ }^{1}$ Faculdade de Odontologia, Universidade Federal de Pernambuco. R. da Alegria 210, Guadalajara. 55820 999 Paudalho PE Brasil. chrisleymariany@gmail.com

${ }^{2}$ Departamento de

Medicina Social,

Universidade Federal de Pernambuco. Recife PE

Brasil.

${ }^{3}$ Institutito Aggeu

Magalhães - Fiocruz/PE, Centro Universitário Tabosa de Almeida. Caruaru PE

Brasil.

${ }^{4}$ Programa de Pós-

Graduação em Saúde

Coletiva, Universidade

Federal de Pernambuco.

Recife PE Brasil.

\begin{abstract}
Fluoridation is considered an effective and wide-ranging measure in combatting dental caries. Despite being mandatory in Brazil since 1974, the implementation continues to be unequal throughout the country. The objective was to describe and analyze fluorine levels in the waters of the public supply grid of the 2nd macro region of the state of Pernambuco in municipalities with 50,000 inhabitants or more. This is a descriptive study based on a comparison of data from Pernambuco Sanitation Company (Compesa), the Vigifluor Project, the Water Quality Surveillance Information System for Human Consumption (Sisagua) the Brazilian Institute of Geography and Statistics (IBGE) and the National Sanitation Information System (SNIS), on the fluoridation of water in municipalities of the 2nd health macro region of Pernambuco. Although the municipalities studied do not have artificial fluoridation, significant levels of natural fluorine were found in the sources that supply the regions. However, these levels of fluorine do not remain constant in the waters of the supply network of the municipalities studied, therefore there is no effective prevention against caries. Artificial fluoridation is an effective measure in preventing caries and should therefore be expanded in regions that are not yet fluoridated.

Key words Water supply, Fluoridation, Dental caries, Dental fluorosis
\end{abstract}

Resumo A fluoretação é considerada uma medida eficaz e de grande abrangência no combate à cárie dentária. Apesar de ser obrigatória no Brasil desde 1974, sua implantação permanece de forma desigual no país. Teve-se como objetivo descrever e analisar os teores de flúor nas águas da rede pública de abastecimento da $2^{a}$ macrorregião do estado de Pernambuco em municípios com 50.000 habitantes ou mais. Trata-se de um estudo descritivo a partir da comparação de dados da Companhia Pernambucana de Saneamento (Compesa), do projeto Vigiflúor, do Sistema de Informação de Vigilância da Qualidade da Água para Consumo Humano (Sisagua), do Instituto Brasileiro de Geografia e Estatística (IBGE) e do Sistema Nacional de Informação sobre Saneamento (SNIS) acerca da fluoretação de águas em municípios da $2^{a}$ macrorregião de saúde de Pernambuco. Apesar dos municípios estudados não possuírem fluoretação artificial, teores significativos de flúor natural foram encontrados nos mananciais que abastecem a região. No entanto, esses valores de flúor não permanecem constantes nas águas da rede de abastecimento dos municípios estudados, não havendo, portanto, efeito preventivo contra a cárie. A fluoretação artificial é uma medida eficaz na prevenção da cárie, portanto deve ser expandida nas regiões ainda não fluoretadas.

Palavras-chave Abastecimento de água, Fluoretação, Cárie dentária, Fluorose dentária 


\section{Introdução}

Por muito tempo a cárie era analisada apenas do ponto de vista biológico e a presença microbiana era a justificativa de sua ocorrência. Com o acréscimo de novos modelos explicativos, foi destacada a importância de avaliar o contexto social dos indivíduos no processo saúde-doença, portanto a doença cárie é um problema complexo, multifatorial e com características populacionais ${ }^{1}$. O ataque desigual da doença decorre não só de variações biológicas inevitáveis, mas das diferenças que têm origem nas desigualdades de ordem social que repercutem no processo saúde-doença ${ }^{2}$. A redução da prevalência geral da cárie no Brasil e em outros países decorre principalmente do acesso a água e dentifrícios fluoretados ${ }^{2,3}$.

A fluoretação de águas de abastecimento público como um método preventivo contra a cárie é considerada na atualidade uma medida amplamente aceita e consolidada ${ }^{4}$. A medida é reconhecida como um importante fator para o declínio da prevalência da cárie dentária ${ }^{5,6}$.

O país pioneiro na fluoretação foram os Estados Unidos, promovendo a adição de fluoretos às águas da cidade de Grands Rapids, no estado de Michigan, em 1945. No Brasil, a fluoretação ocorreu inicialmente em 1953, com a adição de fluoreto às águas da cidade de Baixo Guandu, no Espírito Santo ${ }^{4}$.

Apesar de a fluoretação de águas ser obrigatória desde 1974 no Brasil onde exista estações de tratamento de água (ETAS), em várias grandes cidades brasileiras a medida não é executada. Porém, nas duas últimas décadas do século XX, baseando-se no princípio constitucional da universalização das ações e dos serviços de saúde, visou-se a expansão da fluoretação da água de abastecimento público como um método de intervenção em saúde com caráter universal ${ }^{7}$. A medida é uma estratégia importante da política nacional para intervenção sobre as desigualdades em saúde bucal ${ }^{8}$.

A implantação da fluoretação é considerada a forma mais ampla e socialmente justa de garantir o acesso da população ao flúor ${ }^{9}$. Analisando o avanço da fluoretação no país na primeira década do século XXI, foi observado que a taxa de cobertura da fluoretação de águas aumentou de $67,7 \%$ para $76,3 \%$, um crescimento de $8,6 \%$ quando comparado ao ano de $2000^{10}$. Em seu estudo, Roncalli e colaboradores ${ }^{11}$ concluem que esta cobertura em municípios brasileiros com mais de 50 mil habitantes alcança um percentual de 70,2\%, 4,2 pontos abaixo da estimativa divulgada para o ano de 2008. Apesar dos avanços, os estados com menores índices socioeconômicos possuem os per- centuais mais baixos de cobertura da fluoretação de águas. O Nordeste constitui o maior desafio. A Companhia Pernambucana de Saneamento (Compesa) não disponibiliza a fluoretação nos seus sistemas municipais de abastecimento ${ }^{12}$, demonstrando que, mesmo existindo legislação e ações concretas, há um longo caminho a percorrer para a efetivação total dessa política.

O flúor é utilizado nas ETAS e poços artesianos sob a forma de ácido Fluossilícico ${ }^{8}$. Quando há a suspensão da fluoretação das águas de determinada região, a medida não exerce sua ação de combate contra a cárie e os índices da doença, que haviam sido reduzidos devido à ação preventiva do flúor, podem crescer $^{13}$.

A Portaria no 635, de 26 de dezembro de 1975, estabelece normas para uma fluoretação segura de águas. Nela estão descritos os limites recomendados para a concentração de flúor nas águas de acordo com a média das temperaturas máximas diárias. Para a maioria das cidades brasileiras, a concentração ótima é de 0,70 ppm $^{13}$. A adição do flúor nas ETAS deve ser executada e monitorada, visando a manutenção de índices de flúor que sejam efetivos no controle da cárie e seguros quanto ao risco de fluorose dentária 5 . A fluorose dentária é resultado da ingestão crônica de flúor durante o desenvolvimento dental, e se caracteriza clinicamente por mudanças na opacidade do esmalte dental, com sua severidade dependendo da dose diária de flúor ingerida e do tempo de exposição ${ }^{3}$. A ingestão sistêmica do flúor tem sido associada a alguns efeitos colaterais além da fluorose dentária, como toxicidade aguda ou crônica, fluorose óssea, efeitos na tireóide e na inteligência ${ }^{14}$. No entanto, exceto a fluorose dentária, não há evidências de que o flúor na água em concentrações consideradas ótimas cause outros efeitos sistêmicos em seres humanos. Quando associada a águas fluoretadas com ótimas concentrações de flúor, a fluorose dentária é leve e não afeta a qualidade de vida dos indivíduos ${ }^{14}$.

É essencial que os serviços de vigilância avaliem os índices regionais do fluoreto, garantindo a existência de índices ótimos de flúor ${ }^{15}$. A realização do heterocontrole é de suma importância e deve ser realizado de preferência pela Vigilância Sanitária por meio da coleta de amostras de água na rede de abastecimento, visando a garantia da qualidade da água e a existência teores ideais de flúor 6 .

Estima-se que são poucas as regiões no Brasil cuja ocorrência natural de fluoreto atinja concentrações entre 1,0 e 1,5 mg/FL. No entanto, para prevenir a ocorrência da fluorose dentária, 
devem ser assegurados pelas autoridades públicas de todos os níveis de governo (federal, estaduais e municipais) e pelas empresas de saneamento concentrações de flúor natural que promovam baixo risco para fluorose dentária ${ }^{16}$. A deficiência na vigilância dos teores dessa substância em nosso país ${ }^{8}$ justifica a existência de estudos como este, que avaliem as concentrações de flúor natural nas regiões.

Diante da problemática exposta, este estudo tem como finalidade descrever e analisar os teores de flúor nas águas da rede pública de abastecimento da $2^{\text {a }}$ macrorregião do estado de Pernambuco em municípios com 50.000 habitantes ou mais. Embora este estudo aborde a referida macrorregião, seus achados e metodologia de pesquisa podem ser replicados para os demais municípios brasileiros.

\section{Método}

Trata-se de um estudo observacional descritivo, realizado a partir da utilização de dados secundários oriundos do projeto Vigiflúor, do Sistema de Informação de Vigilância da Qualidade da Água para Consumo Humano (Sisagua), e da Compesa, sobre a fluoretação de águas em municípios maiores de 50.000, localizados na $2^{\text {a }}$ macrorregião de saúde de Pernambuco, e de dados do Instituto Brasileiro de Geografia e Estatística (IBGE) e do Sistema Nacional de Informação sobre Saneamento (SNIS) a respeito da população residente nos municípios escolhidos e com acesso à água tratada, respectivamente.

O projeto Vigiflúor é um estudo multicêntrico voltado à descrição da cobertura populacional da fluoretação das águas da rede pública de abastecimento em municípios com mais de $50 \mathrm{mil}$ habitantes na primeira metade da segunda década do século XXI. Pretende também identificar as localidades que vêm desenvolvendo atividades de vigilância dessa medida em âmbito municipal e estadual. De modo complementar, foi analisada laboratorialmente a concentração de fluoreto em localidades selecionadas, a fim de confirmar ou conhecer o teor do halogênio presente em águas de abastecimento público para consumo humano.

O estado de Pernambuco é dividido em 4 macrorregiões interestaduais de saúde, 12 regiões e 11 microrregiões de saúde ${ }^{17}$. A escolha da macrorregião e dos municípios do estado a serem abordados neste estudo é justificada pela disponibilidade dos laudos de teores de flúor tanto da Compesa quanto do projeto Vigiflúor e pela au- sência de estudos científicos semelhantes a este que abordassem a região. Como critério de inclusão na pesquisa, os municípios participantes deveriam fazer parte da referida macrorregião e possuir 50.000 habitantes ou mais. Os municípios selecionados para participar do estudo foram: Belo Jardim, Bezerros, Gravatá e São Bento do Una. Outros municípios atendiam a nossos critérios, porém optaram pela não participação na pesquisa.

A coleta de dados do projeto Vigiflúor (amostras de água) foi realizada por servidores públicos que atuam no setor de vigilância em saúde (agentes Vigiflúor), sendo devidamente calibrados pelos pesquisadores. A calibração foi realizada mediante palestras e envio de material didático de apoio, fornecendo as informações necessárias para que o planejamento e a execução da coleta de amostras ocorressem de maneira correta.

Para a execução dessa coleta foi adotado o estabelecimento de duas amostras de águas principais - localizadas em unidades distintas - por estação de tratamento ou solução alternativa existente em cada município, complementadas por outras duas amostras de controle - também situadas em unidades distintas -, uma para cada amostra principal. A partir desse critério, é possível avaliar a manutenção dos teores de flúor adicionados nas estações de tratamento (ETAs) ao longo da rede de abastecimento, a estabilidade dos teores de flúor em pontos mais distantes da rede de abastecimento e a existência no município de pontos de fragilidade e de mistura de águas.

Os pontos de coleta das amostras principais foram escolhidos em um local mais próximo da unidade de abastecimento (estação de tratamento de água, reservatório ou solução alternativa) e em outro ponto mais distante da unidade de tratamento (estação de tratamento de água, reservatório ou solução alternativa), preferencialmente em unidades públicas da área da educação ou da saúde.

As amostras de água foram coletadas mensalmente durante três meses, no mesmo ponto de coleta e no mesmo dia, apenas alternando as datas de coleta a cada mês, entre os anos de 2014 e 2018. Ao final dos três meses, 12 amostras haviam sido coletas por cada ETA. Depois de coletadas, foram enviadas para o laboratório de Bioquímica da Faculdade de Odontologia de Piracicaba, da Universidade Estadual de Campinas (FOP-Unicamp), e o teor de fluoreto foi aferido por meio de método eletrométrico.

O Sistema de Informação de Vigilância da Qualidade da Água para Consumo Humano (Si- 
sagua) é um instrumento do Programa Nacional de Vigilância da Qualidade da Água para consumo Humano (Vigiagua), que tem como objetivo auxiliar o gerenciamento dos riscos à saúde relacionados à qualidade da água consumida. O Sisagua armazena informações sobre os sistemas ou soluções alternativas de abastecimento de água. Por meio da análise dos dados armazenados no sistema são gerados relatórios acerca das formas de abastecimento e qualidade da água de consumo humano. Um dos indicadores usados para avaliar essa qualidade é o teor de fluoreto. Esse dado é útil na vigilância da fluoretação ${ }^{18}$. A busca por informações provenientes dos relatórios do Sisagua foi realizada com o objetivo de descrever os teores de flúor encontrado nas águas para consumo humano.

Os dados secundários provenientes de laudos da Compesa são de controle de mananciais que ela executa regularmente, disponibilizados em formato digital para essa pesquisa. Ou seja, tais dados são referentes à quantidade de flúor natural detectada nas águas de mananciais, e não na rede de abastecimento público. Os valores utilizados como referência, tanto nos laudos da Compesa quanto no projeto Vigiflúor, são os valores mínimos e máximos obtidos nos laudos.

Foram realizadas análises descritivas comparativas dos dados coletados, com a sistematização dos resultados em quadros e tabela. Levando em consideração a relação concentração de fluoreto e a variação média das temperaturas máximas diárias do ar de cada região, na faixa entre $26,3^{\circ} \mathrm{C}$ e $32,5^{\circ} \mathrm{C}^{19}$, foi estabelecida a concentração de fluoreto nas águas que oferece benefício máximo para cárie dentária e risco mínimo para fluorose dentária para as localidades selecionadas pela pesquisa, conforme descrito no Quadro 1.

Este estudo está vinculado ao projeto "Cobertura e vigilância da fluoretação da água de abastecimento público no Brasil", ligado ao Centro Colaborador do Ministério da Saúde da Universidade de São Paulo (CECOL/USP), e foi aprovado pelo Comitê de Ética em Pesquisa da FSP-USP.

\section{Resultados}

Os municípios estudados foram: Belo Jardim, Bezerros, Gravatá e São Bento do Una, todos localizados no agreste central e pertencentes à IV Gerência Regional de Saúde. O Quadro 2 apresenta seus respectivos mananciais e gerências regionais.

A maioria dos municípios participantes da pesquisa possui um sistema de abastecimento de água tratada que abrange no mínimo 80\% da população desde 2015. O maior valor percentual foi encontrado em Gravatá, que possui um percentual de aproximadamente $89 \%$ da população com acesso à água tratada. A única exceção foi São Bento do Una, que em 2015 possuía cerca de $47 \%$ da população com acesso a esse benefício, conforme descrito na Tabela 1.

No Quadro 3 podemos verificar os dados dos teores de flúor disponibilizados pela Compesa, pelo projeto Vigiflúor e o resultado da busca de dados no Sisagua. As concentrações de flúor descritas foram os valores máximos e mínimos encontrados pela Compesa e pelo projeto Vigiflúor. Segundo os dados fornecidos pela Compesa, há valores significativos de flúor natural nos mananciais que abastecem a $2^{\mathrm{a}}$ macrorregião do estado. O maior teor de flúor natural, $0,840 \mathrm{mg} /$ FL, foi encontrado nos mananciais dos municípios de Bezerros e Gravatá. Se esta concentração atingisse a rede de abastecimento de águas dos municípios, o flúor exerceria seu máximo efeito preventivo contra a cárie. Esse valor é o mesmo nos dois municípios, pois o manancial que possui esta concentração abastece as duas regiões.

O resultado da análise dos laudos Vigiflúor revela que os valores da substância encontrados nos mananciais desses municípios não chegam a 0,45 mg/FL (concentração que promoveria mínimo benefício contra à cárie). $\mathrm{O}$ valor mínimo encontrado nas águas dos municípios avaliados foi de $0,042 \mathrm{mg} / \mathrm{FL}$ e o valor máximo foi de 0,301 $\mathrm{mg} / \mathrm{FL}$. Esses dois valores foram encontrados no município de Gravatá.

Houve discrepâncias entre os valores de flúor naturais descritos pela Compesa e pelos laudos Vigiflúor, devido aos diferentes métodos de coleta, pois na primeira coleta as amostras foram captadas na origem, e na segunda foram coletadas no destino. Os teores descritos nos laudos Vigiflúor são inferiores aos valores máximos encontrados nos mananciais nos laudos da Compesa, isso significa que, apesar de presente nos mananciais, os valores de flúor não se mantêm constantes ao longo da rede de abastecimento de cada município. Não foram encontradas informações no Sisagua sobre os teores da substância nas águas dos municípios investigados.

Além disso, comparando os resultados observados com os parâmetros dos valores de flúor na rede de abastecimento público que promoveriam máximo benefício, bem como mínimo risco à saúde nas regiões com a temperatura média entre $26,3^{\circ} \mathrm{C}$ e $32,5^{\circ} \mathrm{C}$, verificamos que os teores de flúor existentes nos mananciais que abastecem os municípios da $2^{\text {a }}$ macrorregião do estado de Per- 
Quadro 1. Consenso sobre benefício máximo e risco mínimo para teores de flúor na água de abastecimento público em temperaturas médias anuais entre $26,3^{\circ} \mathrm{C}$ e $32,5^{\circ} \mathrm{C}$.

\begin{tabular}{|l|c|c|}
\hline $\begin{array}{c}\text { Teor de flúor na água } \\
\text { (em PPM ou mg/FL) }\end{array}$ & $\begin{array}{c}\text { Benefício } \\
\text { (prevenir cárie) }\end{array}$ & $\begin{array}{c}\text { Risco } \\
\text { (produzir fluorose dentária) }\end{array}$ \\
\hline 0,00 a 0,44 & Insignificante & Insignificante \\
\hline 0,45 a 0,54 & Mínimo & Baixo \\
\hline $\mathbf{0 , 5 5}$ a $\mathbf{0 , 8 4} 4^{*}$ & Máximo & Baixo \\
\hline 0,85 a 1,14 & Máximo & Moderado \\
\hline 1,15 a 1,44 & Questionável & Alto \\
\hline 1,45 ou mais & Malefício & Muito Alto \\
\hline
\end{tabular}

* Observa-se que a melhor combinação benefício-risco ocorre na faixa 0,55 a 0,84 mg/FL.

Fonte: Pesquisa Vigiflúor.

Quadro 2. Localização dos municípios escolhidos da 2a macrorregião de saúde com mais de 50 mil habitantes e seus respectivos mananciais e suas gerências regionais.

\begin{tabular}{|l|l|l|l|}
\hline Gerência & \multicolumn{1}{|c|}{ Municípios } & \multicolumn{1}{|c|}{ Localização $^{1}$} & \multicolumn{1}{c|}{ Mananciais $^{2}$} \\
\hline IV & Belo Jardim & Agreste central & $\begin{array}{l}\text { Açude Engenheiro Severino Guerra (Bitury); Barragem } \\
\text { Taboquinhas (Riacho Tabocas); Açude Belo Jardim (Ipojuca). }\end{array}$ \\
\hline IV & Bezerros & Agreste central & Barragem Boa Vista; Açude Brejão; Rio Sirinhaém \\
\hline IV & Gravatá & Agreste central & $\begin{array}{l}\text { Barragem Boa Vista; Açude Brejão; Rio Sirinhaém; Barragem } \\
\text { Amaragi; Açude Riacho Cliper; Barragem Vertentes; Barragem } \\
\text { Brejinho }\end{array}$ \\
\hline IV & São Bento do Una & Agreste central & $\begin{array}{l}\text { Barragem Taboquinhas (Riacho Tabocas); Açude Belo Jardim } \\
\text { (Ipojuca); Açude Engenheiro Severino Guerra (Bitury). }\end{array}$ \\
\hline
\end{tabular}

${ }^{1}$ Fonte: Ministério da Saúde. Plano diretor de regionalização. ${ }^{2}$ Fonte: Agência Nacional de Águas.

Tabela 1. Cobertura populacional e população urbana com acesso à água tratada dos municípios da 2a macrorregião de saúde.

\begin{tabular}{|c|c|c|c|c|}
\hline Municípios & 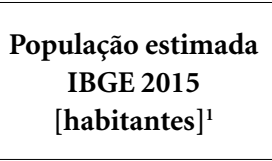 & $\begin{array}{c}\text { Densidade } \\
\text { demográfica } \\
{\left[\mathrm{hab} / \mathrm{Km}^{2}\right]^{1}}\end{array}$ & $\begin{array}{l}\text { População urbana com } \\
\text { acesso à água de } \\
\text { abastecimento } \\
\text { (SNIS/2015) [habitantes] }]^{2}\end{array}$ & $\begin{array}{c}\text { Porcentagem (\%) } \\
\text { da população com } \\
\text { acesso a água de } \\
\text { abastecimento }\end{array}$ \\
\hline Belo Jardim & 75.462 & 111,83 & 60.669 & 80,39 \\
\hline Bezerros & 60.386 & 119,53 & 48.789 & 80,79 \\
\hline Gravatá & 81.893 & 150,87 & 73.246 & 89,44 \\
\hline São Bento do Una & 57.659 & 74,03 & 27.118 & 47,03 \\
\hline
\end{tabular}

${ }^{1}$ Fonte: Instituto Brasileiro de Geografia e Estatística. ${ }^{2}$ Fonte: Sistema Nacional de Informações sobre Saneamento.

nambuco são insignificantes quanto à prevenção da cárie dentária.

\section{Discussão}

O flúor pode ser administrado topicamente em consultórios ou por dentifrícios, porém é provável que a fluoretação de águas atinja a população de forma mais ampla e regular'. Baseado nos dados da Tabela 1, podemos inferir que, exceto em São Bento do Una, a fluoretação artificial nos demais municípios seria significativamente impactante, pois beneficiaria a maioria dos munícipes, já que no mínimo $80 \%$ de seus moradores possuem acesso à água encanada, e cidades como Gravatá teriam aproximadamente $90 \%$ de sua população beneficiada. A adição do fluoreto na água de abastecimento não garante o alcance universal dos munícipes ao flúor. Para isso, faz-se 
Quadro 3. Teores de Flúor presentes nos mananciais da 2a macrorregião de saúde de Pernambuco em municípios com mais de 50.000 habitantes, segundo Compesa, o Vigiflúor e dados do Sisagua.

\begin{tabular}{|c|c|c|c|c|}
\hline Municípios & Mananciais & $\begin{array}{c}\text { Teores de flúor natural } \\
\text { dos mananciais natural } \\
(\mathrm{mg} / \mathrm{Fl})^{1}(\text { Compesa })\end{array}$ & $\begin{array}{l}\text { Teores de flúor laudo } \\
\text { Unicamp (mg/Fl })^{2} \\
\text { (Vigiflúor) }\end{array}$ & $\begin{array}{c}\text { Dados } \\
\text { Sisagua }^{3}\end{array}$ \\
\hline Belo Jardim & $\begin{array}{l}\text { Açude Engenheiro Severino } \\
\text { Guerra (Bitury); } \\
\text { Açude Belo Jardim (Ipojuca); } \\
\text { Barragem Taboquinhas (Riacho } \\
\text { Tabocas); }\end{array}$ & $\begin{array}{c}0 \\
0,260-0,480 \\
\text { Não encontrado }\end{array}$ & $0,107-0,171$ & $\begin{array}{l}\text { Não } \\
\text { cadastrado }\end{array}$ \\
\hline Bezerros & $\begin{array}{l}\text { Barragem Boa Vista; } \\
\text { Açude Brejão; } \\
\text { Rio Sirinhaém; }\end{array}$ & $\begin{array}{c}0,410-0,460 \\
0-0,840 \\
0 \\
\end{array}$ & $0,14-0,29$ & $\begin{array}{l}\text { Não } \\
\text { cadastrado }\end{array}$ \\
\hline Gravatá & $\begin{array}{l}\text { Barragem Boa Vista; } \\
\text { Açude Brejão; } \\
\text { Rio Sirinhaém; } \\
\text { Barragem Amaragi; } \\
\text { Açude Riacho Cliper; } \\
\text { Barragem Vertentes; } \\
\text { Barragem Brejinho; }\end{array}$ & $\begin{array}{c}0,410-0,460 \\
0-0,840 \\
0 \\
0-0,020 \\
0,040-0,160 \\
0-0,160 \\
0-0,220 \\
\end{array}$ & $0,042-0,301$ & $\begin{array}{l}\text { Não } \\
\text { cadastrado }\end{array}$ \\
\hline $\begin{array}{l}\text { São Bento } \\
\text { do Una }\end{array}$ & $\begin{array}{l}\text { Açude Belo Jardim (Ipojuca); } \\
\text { Açude Engenheiro Severino; } \\
\text { Guerra (Bitury); } \\
\text { Barragem Taboquinhas (Riacho } \\
\text { Tabocas). }\end{array}$ & $\begin{array}{c}0-0,480 \\
0 \\
0,260-0,480 \\
\text { Não encontrado }\end{array}$ & $0,14-0,29$ & $\begin{array}{l}\text { Não } \\
\text { cadastrado }\end{array}$ \\
\hline
\end{tabular}

Fonte: Compesa, Vigiflúor e Sisagua.

necessário um amplo acesso da população à água encanada ou a alguma fonte comunitária de água fluoretada ${ }^{19}$.

Observando o percentual da população com acesso à água tratada em São Bento do Una, verificou-se que em 2015 apenas 47\% da população tinha esse benefício. Isso significa que a fluoretação artificial nesse município cobriria um baixo percentual dos habitantes, ficando parte da população sem acesso a esse benefício. A cobertura não universal do sistema de abastecimento público de águas se constitui como uma fonte de desigualdade no acesso à água fluoretada ${ }^{19}$.

A baixa cobertura do sistema de abastecimento de águas em municípios como São Bento do Una comprometeria a fluoretação artificial na região, pois existe uma associação entre a baixa cobertura e a ausência de fluoretação. Essa associação é demonstrada em nível nacional nas regiões Norte e Nordeste, que apresentam os menores índices populacionais de acesso à água encanada quando comparadas a Sul e Sudeste, e não por acaso possuem os menores índices de cidades fluoretadas. A menor oferta de água tratada constitui uma das causas para a existência de diferenças inter-regionais na implantação da fluoretação de águas no país'. Ampliar o acesso à água tratada nos municípios com menor oferta é importante para a melhoria das condições de saúde da população e da abrangência da fluoretação nas regiões ${ }^{19}$.

Apesar da determinação da obrigatoriedade legal da fluoretação no país ${ }^{4}$ e da ampla cobertura dos sistemas de abastecimento de águas em Belo Jardim, Bezerros e Gravatá, as autoridades responsáveis não implantaram a medida nessas localidades, o que demonstra a existência de outros obstáculos que dificultam a implementação da medida. Alguns empecilhos observados são a omissão do poder público e as piores condições socioeconômicas das cidades, que parecem estar associados à existência de diferenças inter-regionais no acesso à fluoretação $0^{20,21}$.

O fluoreto está presente na natureza em solos e águas ${ }^{22}$. Teores residuais de flúor foram encontrados em diversas regiões do país ${ }^{23}$. Em nosso estudo, observando os dados fornecidos pela Compesa, verificamos que os municípios participantes apresentaram teores naturais da substância em seus mananciais, variando entre 0 e 0,840 $\mathrm{mg} / \mathrm{FL}$. A maior concentração de flúor de ocorrência natural atingiu $0,840 \mathrm{mg} / \mathrm{FL}$, encontrada em Bezerros e Gravatá. Esse teor requer atenção dos responsáveis pela vigilância do fluoreto. 
No Brasil, a concentração de até $1,5 \mathrm{mg} / \mathrm{FL}$ é considerada tolerável, no entanto, de acordo com o decreto Federal 5440/2005, quando a ocorrência natural de flúor atingir teor superior a 0,9 $\mathrm{mg} / \mathrm{FL}$ os responsáveis pelos sistemas e soluções alternativas coletivas de abastecimento de água devem emitir à população o seguinte aviso: "Esta água não deve ser consumida diariamente por menores de oito anos de idade"16.

O estudo de concentrações de flúor in natura é considerado importante, pois a fluoretação artificial das águas de abastecimento público deve ser executada levando em consideração os teores naturais do fluoreto encontrados nas regiões onde a medida será implementada. Outro fator que justifica a importância dessa análise é a possibilidade de populações da zona rural em contato com esse íon serem beneficiadas ou prejudicadas pela concentração residual de flúor ${ }^{24}$.

$\mathrm{O}$ valor máximo de flúor natural encontrado na rede de abastecimento público dos municípios abordados em nossa pesquisa, segundo o laudo Vigiflúor, foi de $0,301 \mathrm{mg} / \mathrm{FL}$ no município de Gravatá. Observando o Quadro 1, verificamos que o teor da substância que promoveria mínimo benefício seria de 0,45 a $0,54 \mathrm{mg} / \mathrm{FL}$, e o que proporcionaria máximo benefício e mínimo risco seria de 0,55 a $0,84 \mathrm{mg} / \mathrm{FL}$. Ou seja, apesar da existência de flúor natural nas regiões estudadas, esses percentuais são insignificantes no combate à cárie, pois não chegam às casas em concentração eficaz para serem um agente de prevenção da cárie. Quando as águas de abastecimento apresentarem teores naturais insuficientes para promover efeito preventivo no combate à cárie, é recomendada a adição de flúor para a implantação da fluoretação artificial $^{20}$, medida que se mostra necessária nos municípios pesquisados.

Há uma maior incidência de cárie em brasileiros de 12 anos nas cidades que não adicionam flúor à água de abastecimento ${ }^{25}$. Um estudo comparativo entre o número médio de dentes permanentes cariados, perdidos e obturados (CPOD) e o Significant Caries Index (SIC) -índice que traduz o impacto da cárie nos indivíduos mais afetados -, realizado em uma população com acesso à água fluoretada e outra sem, ambas com baixa prevalência da doença, com seus participantes fazendo uso de dentrifícios fluoretados e com um padrão similar de distribuição da doença, demonstrou que menores valores médios dos índices CPOD e SIC foram encontrados na população exposta à água fluoretada ${ }^{22}$.

A fluoretação de águas se destaca como uma medida preventiva de enfrentamento à cári ${ }^{26}$, sendo considerada econômica e segura ${ }^{15}$. No entanto é necessária a vigilância dessa medida para manutenção dos índices ideais de flúor. As ações de monitoramento são baseadas no heterocontrole, realizado por meio da análise de dados primários obtidos das amostras coletadas na rede de distribuição de água, ou de dados secundários fornecidos pela empresa responsável pelo abastecimento em cada região do País ${ }^{27}$. O Sisagua apresenta informações insuficientes para o monitoramento da fluoretação das águas, o que dificulta a construção de indicadores de diagnóstico e o planejamento de ações de vigilância em saú$\mathrm{de}^{8}$. Os resultados que encontramos confirmam essa deficiência descrita na literatura.

Os teores de flúor dos municípios estudados não foram encontrados nos dados do Sisagua, o que reflete o déficit na vigilância do fluoreto executada pelas entidades governamentais. Apesar das concentrações encontradas nas águas da rede de abastecimento das regiões avaliadas não promoverem benefícios contra a cárie, encontramos teores significativos de fluoreto nos mananciais que abastecem essas cidades. Indivíduos que utilizam soluções alternativas de abastecimento de água podem ter acesso ao flúor disponível nos mananciais, o que torna essencial a execução da vigilância dos teores da substância, visando a segurança da saúde da população.

Um estudo revelou deficiências no campo da vigilância da fluoretação em diversas capitais brasileiras, na maioria delas houve problemas como: inexistência de coleta, deficiências na análise e na divulgação dos teores e alta prevalência de amostras fora dos padrões no Sisagua. Isso reflete a falta de comprometimento das instituições públicas com a realização das ações de vigilânciaa ${ }^{28,29}$.

Controlar o processo da fluoretação visando a manutenção de índices adequados de flúor é tão importante quanto a continuidade da medida e a inserção da substância nas águas não fluoretadas. Além do controle do tratamento e da distribuição de fluoreto pela empresa responsável, são necessárias ações no âmbito da vigilância sanitária ${ }^{30}$. A ampliação da cobertura de fluoretação das águas requer o fortalecimento das ações de monitoramento do teor de flúor como parâmetro integrante do Vigiágua. A responsabilidade institucional desse monitoramento é das secretarias municipais de saúde ${ }^{30}$.

Apesar das dificuldades, uma das estratégias prioritárias da política nacional de saúde bucal deve continuar sendo a universalização do acesso à água fluoretada ${ }^{24}$. A decisão de não fluoretar é ilegal e socialmente injusta, não havendo argumentos de nenhuma natureza (técnicos, políticos ou orçamentários) que justifiquem a ausência da 
medida em Pernambuco. Além disso, a Secretaria Estadual de Saúde, com o auxílio dos municípios, possui a infraestrutura necessária para a execução da vigilância dos teores de flúor nas águas, com vistas a garantir o máximo benefício no combate à cárie ${ }^{31}$.

\section{Conclusão}

Os quatro municípios da $2^{\text {a }}$ macrorregião do estado de Pernambuco participantes desse estudo (Belo Jardim, Bezerros, Gravatá e São Bento do Una) possuem teores naturais de flúor significativos em seus mananciais e nas águas da rede de abastecimento público. No entanto, os valores encontrados nos mananciais não se mantêm estáveis ao longo da rede de abastecimento público, sendo reduzidos a concentrações insignificantes para promover efeito preventivo contra a cárie, requerendo portanto a implementação da fluoretação artificial das águas da rede de abastecimento público dessa região e a vigilância dos teores de fluoreto.

Os órgãos que possuem a responsabilidade de vigiar as concentrações desse íon têm sido deficientes na execução desta tarefa. Ressalta-se que a vigilância deve ser realizada de maneira eficaz e constante, visando a preservação da saúde da população.

Este estudo reforça a necessidade da execução da fluoretação artificial nos sistemas de abastecimento público dos municípios estudados e nos demais municípios de Pernambuco e o fortalecimento das ações de monitoramento da fluoretação que garantam a manutenção de níveis de flúor que promovam máximo benefício no combate à cárie e mínimo risco de fluorose dentária para a população.

\section{Colaboradores}

CMO Freitas, PJL Martelli e N Figueiredo trabalharam na concepção, delineamento, análise e interpretação dos dados, bem como na redação do artigo e na aprovação da versão a ser publicada. GF Fernandes e ML Brasil trabalharam na revisão crítica e na aprovação da versão a ser publicada. 


\section{Referências}

1. Costa SM, Adelário AK, Vasconcelos M, Abreu MHNG. Modelos explicativos da cárie dentária: do organicista ao ecossistêmico. Pesq Bras Odontoped Clin Integr 2012; 12(2):285-291.

2. Narvai PC, Frazão P, Roncalli AG, Antunes JLF. Cárie dentária no Brasil: declínio, polarização, iniquidade e exclusão social. Rev Panam Salud Publica 2006; 19(6):385-393

3. Brasil. Ministério da Saúde. Guia de recomendações para o uso de fluoretos no Brasil. Brasília: Ministério da Saúde; 2009.

4. Mário Júnior RJ, Narvai PC. Aspectos históricos e perspectivas da fluoretação de águas de abastecimento público no estado de São Paulo. Bepa 2011; 8(90):2429.

5. Ramires I, Buzalaf MAR. A fluoretação da água de abastecimento público e seus benefícios no controle da cárie dentária - cinquenta anos no Brasil. Cien Saude Colet 2007; 12(4):1057-1065.

6. Peres SHCS. Perfil epidemiológico de cárie dentária, em cidades fluoretadas e não fluoretadas, na região centro - oeste do estado de São Paulo [dissertação]. Bauru: Faculdade de Odontologia de Bauru; 2001.

7. Narvai PC. Cárie dentária e flúor: uma relação do século XX. Cienc Saude Colet 2000; 5(2):381-392.

8. Frazão P, Soares, CCS, Fernandes GF, Marques RGA, Narvai PC. Fluoretação da água e insuficiências no sistema de informação da política de vigilância à saúde. Rev Assoc Paul Cir Dent 2013; 67(2):94-100.

9. Antunes JLF, Narvai, PC. Políticas de saúde bucal no Brasil e seu impacto sobre as desigualdades em saúde. Rev Saude Publica 2010; 44(2):360-365.

10. Frazão P, Narvai PC. Water fluoridation in Brazilian cities at the first decade of the 21st century. Rev Saude Publica 2017; 51(47):1-11.

11. Roncalli AG, Noro LRA, Cury JA, Zilbovicius C, Pinheiro HHC, Ely HC, Narvaí PC, Frazão P. Fluoretação da água no Brasil: distribuição regional e acurácia das informações sobre vigilância em municípios com mais de 50 mil habitantes. Cad Saude Publica 2019; 35(6):1-12.

12. Carvalho NP. Fluoretação nos sistemas de abastecimento de água nos municípios que compõe a VII Regional de Saúde - Salgueiro - PE. Projeto de Intervenção [monografia]. Pernambuco: Centro de Pesquisa Aggeu Magalhães, Fundação Oswaldo Cruz; 2012.

13. Cury JA. Fluoretação da água: riscos, benefícios e sugestões. ROBRAC 1992; 2(5):32-33.

14. Cury JA, Ricomini-Filho AP, Berti FLP, Tabchoury CPM. Systemic effects (risks) of water fluoridation. Braz Dent J 2019; 30(5):421-428.

15. Timóteo WO, Serra JCV. Problemática do abastecimento de água em uma população crescente: caso específico Palmas - TO. Engenharia Ambiental - Espírito Santo do Pinhal 2013; 10(2):220-230.

16. Frazão P, Peres MA, Cury JA. Qualidade da água para consumo humano e concentração de fluoreto. Rev Saude Publica 2011; 45(5):964-973.

17. Secretaria Estadual de Saúde de Pernambuco. Plano diretor de regionalização. Recife: Secretaria Estadual de Saúde de Pernambuco; 2011.

18. Brasil. Ministério da Saúde. Manual de procedimentos de entrada de dados do Sisagua. Brasília: Ministério da Saúde; 2016.
19. Centro Colaborador do Ministério da Saúde em Vigilância da Saúde Bucal (CECOL-USP). Universidade de São Paulo CECOL/USP apresenta sugestões na Consulta Pública sobre a Portaria MS 2.914, de 12/12/2011. São Paulo: CECOL; 2011.

20. Antunes JLF. Intervenções em saúde pública e seu impacto nas desigualdades sociais em saúde. Tempo Social 2015; 27(1):161-175.

21. Aguiar RGL, Narvai PC. Fluoretação da água: significados e lei da obrigatoriedade na visão de lideranças em saúde. Rev Assoc Paul Cir Dent 2015; 69(3):266271.

22. Freire MCM, Reis SCG, Figueredo N, Peres KG, Moreira RS, Antunes JLF. Determinantes individuais e contextuais da cárie em crianças brasileiras de 12 anos em 2010. Rev Saude Publica 2013; 47(3):40-49.

23. Prado ASSO. A relação entre prevalência de cárie dentária e ausência de fluoretação da água [monografia]. Lagoa Santa: Universidade Federal de Minas Gerais; 2012.

24. Martins ETL, Forte FDS, Sampaio FC. Mapeamento dos teores residuais de flúor de águas da zona rural do sertão nordestino do Brasil. Rev Odontol UNESP 2012; 41(3):147-153.

25. Frois AG. Revisão de literatura sobre o controle do flúor e sua importância na prevenção da cárie [monografia]. Lagoa Santa: Universidade Federal de Minas Gerais; 2013.

26. Narvai PC, Cruz MGB. Cárie e água fluoretada em dois municípios brasileiros com baixa prevalência da doença. Rev Saude Publica 2018; 52(28):1-11.

27. World Health Organization (WHO). Oral health: action plan for promotion and integrated disease prevention. Geneva: WHO; 2006.

28. Ferreira RGLA, Marques RAA, Menezes LMB, Narvai PC. Múltiplos aspectos do uso do flúor em saúde pública na visão de lideranças da área de saúde. Cien Saude Colet 2013; 18(7):2139-2146.

29. Cesa K, Abegg C, Aerts DA. Vigilância da fluoretação de águas nas capitais brasileiras. Epidemiol Serv Saude 2011; 20(4):547-555.

30. Narvai PC. Vigilância sanitária da fluoretação das águas de abastecimento público no município de São Paulo, Brasil, no período 1990-1999 [tese]. São Paulo: Universidade de São Paulo; 2001.

31. Anjos GAS, Fernandes GF. Fluoretação das águas de abastecimento público no estado de Pernambuco: um resgate histórico. Odontol Clin-Cient 2015; 14(1):559564.

Artigo apresentado em 18/02/2019

Aprovado em 04/12/2019

Versão final apresentada em 06/12/2019

Editores-chefes: Romeu Gomes, Antônio Augusto Moura da Silva 
